\title{
SOSIALISASI PENDIDIKAN KARAKTER BERBASIS KEARIFAN LOKAL PADA ANAK-ANAK DENGAN MEDIA PUZZLE DI KELURAHAN PENFUI TIMUR KECAMATAN KUPANG TENGAH KABUPATEN KUPANG
}

\author{
Susilo Setyo Utomo ${ }^{1 *}$, Djakariah ${ }^{2}$, Jonas Thene ${ }^{3}$ \\ ${ }^{1 *}$ Program Studi Pendidikan Sejarah, Universitas Nusa Cendana \\ ${ }^{2}$ Program Studi Pendidikan Sejarah, Universitas Nusa Cendana \\ ${ }^{3}$ Program Studi Pendidikan Sejarah, Universitas Nusa Cendana \\ *Corresponding author: \\ E-mail : susilosetyoutomo@staf.undana.ac.id
}

Diterima 6 November 2019, Disetujui 18 November 2019

\begin{abstract}
ABSTRAK
Pengabdian kepada Masyarakat dilaksanakan di Kelurahan Penfui Timur Kecamatan Kupang Tengah Kabupaten Kupang. Target luaran yang diharapkan melalui kegiatan ini dapat dirumuskan sebagai berikut: (1) Anak-anak di Desa Penfui Timur dapat mengembangkan karakter, selain belajar formal. (2) Anak-anak di Desa Penfui Timur dapat mengaplikasikan pengalaman dan ilmu yang kami berikan dengan sarana puzzle, selama maupun setelah kegiatan ini berlangsung. (3) Anak-anak mengenal kekayaan dan nilai-nilai sosial budaya yang mereka miliki dan mengandung nilai-nilai karakter di dalamnya yang dapat diterapkan dalam kehidupan sehari-hari. (4) Anak-anak di Desa Penfui Timur dapat mencintai dan melestarikan budaya mereka. Metode yang digunakan dalam Pengabdian kepada masyarakat ini didesain dalam bentuk ceramah, diskusi dan sharing pendapat baik dengan anak maupun orang tuanya dalam rangka untuk menjawab masalah yang berkaitan dengan upaya menanamkan karakter berbasis nilai-nilai kearifan lokal pada anak-anak di Penfui Timur dan permainan anak-anak dengan media puzzle. Media puzzle sangat pas untuk dipakai karena puzzle identik dengan anak yaitu dunia bermain. Puzzle juga memiliki manfaat untuk meningkatkan keterampilan kognitif, keterampilan motorik halus, keterampilan sosial, keterampilan berinteraksi dengan orang lain, melatih koordinasi mata dengan tangan, melatih logika, melatih kesabaran, dan memperluas pengetahuan. Hasil dari kegiatan ini menunjukkan bahwa puzzle berbasis kearifan lokal memuat nilai-nilai karakter sebagai salah satu sarana dalam mengembangkan karakter pada anak-anak. Dengan pertimbangan bahwa anak-anak lebih menyukai permainan ini karena dianggap menarik dan tidak membosankan.
\end{abstract}

Kata Kunci: Pendidikan Karakter, Kearifan Lokal, Media Puzzle

\begin{abstract}
Community Service is carried out in Penfui Timur Village, Kupang Tengah District, Kupang Regency. The expected output targets through this activity can be formulated as follows: (1) Children in East Penfui Village can develop their character, in addition to formal learning. (2) Children in Penfui Timur Village can apply the experience and knowledge that we provide using puzzles, both during and after this activity takes place. (3) Children recognize the wealth and socio-cultural values they have and contain character values that can be applied in daily life. (4) Children in East Penfui Village can love and preserve their culture. The method used in community service is designed in the form of lectures, discussions, and sharing of opinions both with children and their parents to answer problems related to efforts to instill character-based values of local wisdom in children in East Penfui and children's play with puzzle media. The media puzzle is very fitting to use because a puzzle is identical to children, namely the world of play. Puzzles also have benefits for improving cognitive skills, fine motor skills, social skills, interacting skills with others, training eye coordination with hands, training logic, training patience, and expanding knowledge. The results of this activity show that local wisdom-based puzzles contain character values as a means of developing character in children. With the consideration that children prefer this game because it is considered interesting and not boring.
\end{abstract}

Keywords: Character Education, Local Wisdom, Media Puzzle 


\section{PENDAHULUAN}

Fenomena tentang degradasi moral menjadi isu yang mengemuka di masyarakat saat ini. Baru-baru kita dihebohkan dengan kasuskasus korupsi yang dilakukan oleh seorang pimpinan partai politik yang masih berusia muda. Realitas yang terjadi tersebut menegaskan perlunya penanaman pendidikan karakter khususnya bagi anak-anak.

Pendidikan karakter adalah pendidikan untuk membentuk kepribadian seseorang melalui pendidikan budi pekerti, yang hasilnya terlihat dalam tindakan nyata seseorang, yaitu tingkah laku yang baik, jujur, bertanggung jawab, menghormati hak orang lain, kerja keras, dan sebagainya (Lickona, 1992:12)

Mengingat pentingnya pendidikan karakter dalam interaksi sosial masyarakat maka dari itu perlunya penanaman pendidikan karakter sejak usia dini. Proses pengembangan nilai-nilai budaya dan karakter bangsa adalah sebuah proses panjang dimulai dari usia dini. Pendidikan karakter dibentuk pada lingkungan internal maupun eksternal seorang anak. Pendidikan karakter pada lingkungan internal dimulai dari lingkungan keluarga. Sedangkan pendidikan karakter pada lingkungan eksternal meliputi masyarakat dan lingkungan sekolah. Maka dari itu harus adanya kerjasama antara pihak di dalam lingkungan eksternal maupun internal.

Perumahan Pondok Indah Matani merupakan perumahan yang terletak di Kelurahan Penfui Timur, Kupang Tengah Kabupaten Kupang. Penduduknya terdiri dari berbagai masyarakat dari latarbelakang yang berbeda-beda. Di Perumahan ini terdapat banyak anak-anak baik itu pendatang dari luar kupang ataupun dari masyarakat sekitar Kupang sendiri atau bisa dikatakan penduduknya multi etnis.

Dunia anak identik dengan bermain.

Puzzle merupakan media yang mengandung unsur permainan, oleh karenanya maka puzzle dinilai sangat pas untuk digunakan sebagai media dalam menanamkan pendidikan karakter terhadap diri anak-anak. Puzzle merupakan sebuah permainan untuk menyatukan pecahan keeping untuk membentuk suatu gambar atau tulisan yang telah ditentukan. Istilah puzzle ini oleh masyarakat Indonesia dikenal sebagai permainan bongkar pasang. Puzzle sebagai alat untuk permainan yang mengharuskan kita sebagai pemain menyusun potongan-potongan puzzle (Indriana, 2011:23).

Berdasarkan pengertian tersebut dapat disimpulkan bahwa permainan puzzle adalah sebuah media yang pemainnya harus menyusun atau menyatukan pecahan keeping untuk membentuk sebuah gambar atau kata yang telah ditentukan. Puzzle merupakan media pembelajaran yang sederhana akan tetapi puzzle memiliki manfaat antara lain; 1) meningkatkan keterampilan kognitif, berkaitan dengan kemampuan anak untuk memecahkan masalah, 2) meningkatkan kemampuan motorik halus, 3) meningkatkan keterampilan sosial, berkaitan dengan keterampilan berinteraksi dengan orang lain, 4) melatih koordinasi mata dan tangan, 5) melatih logika, 6) melatih kesabaran, 7) memperluas pengetahuan.

Tujuan utama kami membuat program ini adalah munculnya karakter yang berbasis kearifan lokal dari anak-anak di Desa Penfui Timur tersebut karena dengan hal-hal tersebut kami berharap anak-anak mampu bersaing dengan individu lain dalam berbagai konteks. Untuk menumbuhkan karakter tersebut pada anak-anak di Desa Penfui Timur diperlukan kegiatan secara bertahap agar tercipta kebiasaan yang teratur.

Berdasarkan hal di atas, kami menawarkan solusi dengan penanaman pendidikan karakter pada anak dengan media puzzle. Gambar yang terdapat pada puzzle di dalamnya memuat nilai-nilai karakter yang berbasis budaya sebagai salahsatu sarana dalam mengembangkan karakter pada anak-anak di Desa Penfui Timur. Dengan pertimbangan bahwa anak-anak lebih menyukai media permainan dianggap menarik dan tidak membosankan. Dengan media puzzle tersebut mereka dapat melihat contoh-contoh kearifan lokal dan keteladanan yang dapat diambil nilai karakternya. Selain itu kami selingi dengan beberapa permainan bukan pendidikan formal seperti yang didapat anak-anak di sekolah.

Berdasarkan gambaran pada analisis situasi, maka yang menjadi masalah dalam kegiatan ini adalah

1. Masih banyak anak-anak di Desa Penfui Timur yang kurang paham bahwa di dalam budaya mereka terdapat nilai-nilai karakter yang dapat dicontoh dan diterapkan dalam kehidupan sehari-hari.. Jika anak-anak yang merupakan generasi penerus bangsa tidak memiliki karakter kuat sesuai dengan budaya maka akan terombang ambing tergerus arus globalisasi yang tidak bisa terbendung lagi.

2. Banyak anak-anak yang sudah mendapat pengaruh negatif dari media seperti televisi, handphone sehingga banyak yang berani 
dengan orangtua dan tidak sopan, tidak jujur, suka berkelahi dengan teman, dll. Ini perlu mendapatkan perhatian yang serius agar karakter mereka baik sesuai budaya.

\section{METODE KAJIAN}

Untuk merealisasikan kegiatan pengabdian kepada masyarakat agar sasaran tercapai dengan metode sebagai berikut:

a. Memberikan materi dengan menggunakan media puzzle berbasis kearifan lokal seperti tentang kegiatan keseharian dan acara-acara budaya.

b. Mengundang anak-anak yang ada di Kelurahan Penfui Timur dan perwakilan bapak/ibu setempat.

c. Permainan anak-anak dengan puzzle (berbasis kearifan lokal budaya)

d. Diskusi dan dialog

e. Tempat kegiatan: di Kelurahan Penfui Timur Kabupaten Kupang

\section{HASIL DAN PEMBAHASAN}

1. Puzzle dapat menjadi sarana untuk mengembangkan karakter pada anak-anak

Pendidikan karakter berbasis kearifan lokal menjadi salah satu solusi alternative bagi pelaksanaan pendidikan karakter sesuai dengan keunggulan lokal yang dimiliki masing-masing daerah dalam mencegah dan mengurangi pergeseran nilai kemanusiaan akibat adanya arus globalisasi. Hal ini sejalan dengan fungsi pendidikan nasional yaitu mengembangkan kemampuan dan membentuk watak serta peradaban bangsa yang bermartabat dalam rangka mencerdaskan kehidupan bangsa, dan untuk mengembangkan potensi peserta didik agar menjadi manusia manusia yang beriman dan bertakwa kepada Tuhan Yang Maha Esa, Berakhlak mulia, sehat, berilmu, cakap kreatif, mandiri dan menjadi warga Negara yang demokratis serta bertanggung jawab. Selain itu diarahkan untuk membentuk watak atau karakter bangsa, sehingga mampu menjadi bangsa yang beradab dan bermartabat luhur serta mampu menjadi bangsa yang memiliki keunggulan tertentu dibanding bangsa-bangsa lain.

Media Puzzle berbais kearifan lokal pada anak-anak Penfui Timur ternyata dapat membantu anak-anak lebih mudah memahami nilai-nilai karakter. Puzzle yang menjadi salahsatu media penanaman pendidikan karakter disukai anak-anak. Pesan-pesan moral yang ada dalam setiap Puzzle berbasis kearifan lokal yang mengandung budaya sehari-hari mereka sehingga kontekstual dan mudah dimengerti.
Pendidikan karakter menjadi sangat penting terutama anak-anak karena karakter menjadi dasar seorang individu untuk bersaing di masa yang akan datang. Cerdas secara intelektual tidak menjamin seseorang untuk sukses, karena sukses merupakan kombinasi dari kecerdasan intektual, emosional dan spiritual. Hal tersebut tentu tidak terlepas dari peran serta orang tua yang merupakan sosialisasi paling utama bagi anak-anak. Untuk itu dalam penelitian ini diadakan sosialisasi juga terhadap orang tua tentang pentingnya pendidikan karakter bagi anak.

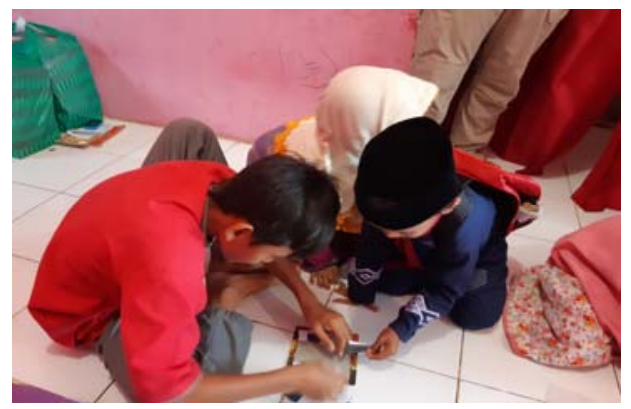

Gambar 1. Kegiatan Permainan puzzle

(Sumber: Dokumentasi Pribadi, 2019)

Selain menggunakan media puzzle berbasis kearifan lokal sebagai media penghantar dalam penanaman karakter bagi anak, kami juga memberikan pelatihan parenting untuk orang tua dari peserta didik, hal ini dilakukan untuk menanamkan kesadaran bahwa anak adalah tanggung jawab dan amanah yang harus dijaga. Selain itu kami juga mengajarkan bagaimana perilaku yang baik yang perlu ditanamkan pada anak-anak dalam kehidupan sehari-hari.

Pendidikan karakter dapat ditanamkan tidak hanya ditanamkan secara formal disekolah tetapi perlu ditanamkan juga diluar sekolah (informal), sehingga diharapkan dengan adanya keseimbangan penanaman pendidikan karakter baik informal maupun formal anak-anak tidak hanya cerdas dan pandai dalam bidang akademik tetapi juga memiliki dan menjunjung tinggi nilainilai budaya yang ada sebagai jati diri dan keunggulan bangsa. Berdasarkan hasil analisis dan pembahasan maka dapat disimpulkan bahwa media berbasis budaya dapat menjadi sarana bagi anak-anak dalam mengembangkan karakter. 
2. Media puzzle berbasis kearifan lokal ini dapat diaplikasikan anak-anak

Pada dasarnya, anak-anak yang memiliki kualitas karakter rendah adalah anak yang tingkat perkembangan emosi-sosialnya rendah, sehingga anak beresiko besar mengalami kesulitan belajar, berinteraksi 114ocial, dan tidak mampu mengontrol diri. Mengingat pentingnya penanaman karakter pada usia dini, maka pendidikan karakter merupakan hal yang sangat penting untuk dilaksanakan.

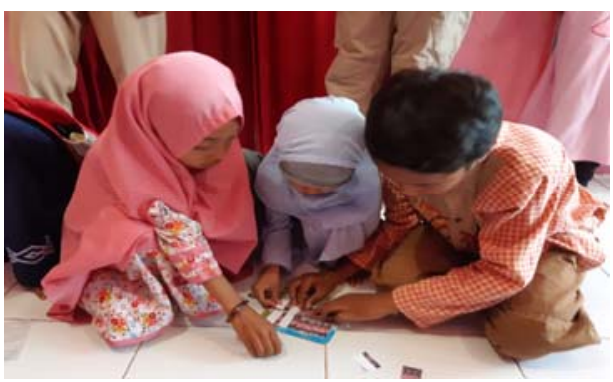

Gambar 2. Permainan puzzle anakanak.

(Sumber: Dokumentasi Pribadi, 2019)

Penanaman nilai-nilai karakter sangat memerlukan pembiasaan sejak dini termasuk pada tingkatan anak-anak. Anak mulai dibiasakan mengenal perilaku mana yang baik dan mana yang buruk, mana yang boleh dilakukan dan mana yang tidak boleh dilakukan, sehingga diharapkan pada gilirannya menjadi sebuah kebiasaan. Perlahan-lahan sikap dan nilai-nilai yang ditanamkan tersebut akan terinternalisasi ke dalam dirinya dan membentuk kesadaran bersikap dan tindakan sampai usia dewasa

Pendidikan karakter berbasis kearifan lokal yang ditanamkan dengan media puzzle ini diharapkan dapat menghasilkan lingkungan yang kondusif bagi anak-anak di kelurahan Penfui Timur, bagi pertumbuhan anak dan bekal bagi mereka untuk persaingan dimasa yang akan datang. Hal ini ditunjang pendidikan parenting bagi orang tua dapat meneruskan kebiasaan baik yang akan menunjang keberlangsungan bagi program yang telah kami jalankan bagi putra putri mereka.

Karakter sebagai suatu 'moral excellence' atau akhlak dibangun di atas berbagai kebajikan (virtues) yang pada gilirannya hanya memiliki makna ketika dilandasi atas nilainilai yang berlaku dalam budaya (bangsa). Karakter bangsa Indonesia adalah karakter yang dimiliki warga negara bangsa Indonesia berdasarkan tindakan-tindakan yang dinilai sebagai suatu kebajikan berdasarkan nilai yang berlaku di masyarakat dan bangsa Indonesia. Oleh karena itu, Pendidikan Budaya dan Karakter Bangsa diarahkan pada upaya mengembangkan nilai-nilai yang mendasari suatu kebajikan sehingga menjadi suatu kepribadian diri warga negara.

Proses pembelajaran Pendidikan Budaya dan Karakter Bangsa dilaksanakan melalui proses belajar aktif seperti bermian puzzle. Sesuai dengan prinsip pengembangan nilai harus dilakukan secara aktif oleh anak-anak (dirinya subyek yang akan menerima, menjadikan nilai sebagai miliknya dan menjadikan nilai-nilai yang sudah dipelajarinya sebagai dasar dalam setiap tindakan) maka posisi anak-anak sebagai subyek yang aktif dalam belajar.

3. Anak-anak di Kelurahan Penfui Timur tertarik untuk memainkan puzzle berbasis kearifan lokal ini dari awal sampai akhir

Pendidikan karakter adalah budi pekerti plus, yaitu yang melibatkan aspek pengetahuan (cognitive), perasaan (feeling) dan tindakan (action). Menurut Thomas Lickona (1992), tanpa ketiga aspek ini, pendidikan karakter tidak akan efektif, dan pelaksanaannya pun harus dilakukan sistematis dan berkelanjutan. Dengan pendidikan karakter, seorang anak akan menjadi cerdas emosinya. Kecerdasan emosi adalah bekal terpenting dalam mempersiapkan anak menyongsong masa depan, karena dengannya seseorang akan dapat berhasil dalam menghadapi segala macam tantangan termasuk berhasil dalam bidang akademis.

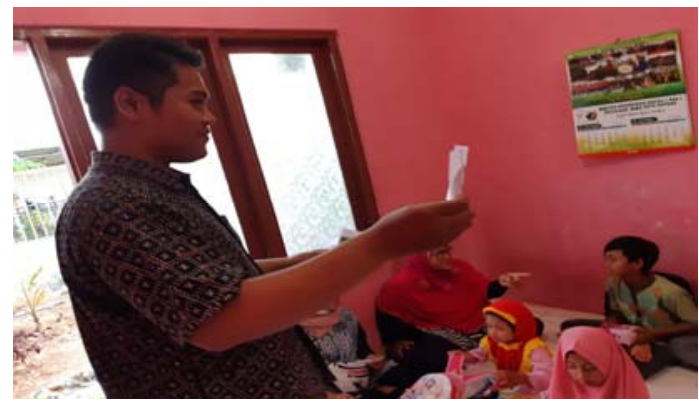

Gambar 3. Pemberian soal kuis pada anak-anak (Sumber: Dokumentasi Pribadi, 2019)

Media puzzle yang digunakan dalam memberikan pendidikan karakter ternyata banyak disukai anak-anak. Hal ini dibuktikan dengan besarnya antusiasme anak-anak dalam menyusun puzzle-puzzle yang telah disiapkan. Mereka tampak serius menyusun puzzle-puzzle tadi. Bahkan mereka tampak tertawa karena di dalam puzzle mereka memainkannya dengan gembira yang di dalamnya bermacam-macam 
kebudayaan dan terselip pesan moral di dalamnya. Dengan demikian memang diperlukan metode dan media yang tepat agar pendidikan karakter mudah di terima oleh anak-anak.

Anak-anak tampak ceria dan senang setelah menyusun puzzle dan setelah itu diberikan kuis untuk dijawab. Soal-soal kuis diberikan sesuai dengan pesan -pesan karakter dan moral yang ada di dalam puzzle dan budaya mereka. Banyaknya anak-anak yang antusias dalam menjawab pertanyaan bahkan berebut menjawab. Permainan dan kuis tampak seru dan menyenangkan. Anak-anak pun menjawab dengan benar dan diberikan reward atau hadiahnya. Dengan demikian mereka belajar tentang budaya sendiri dengan menyenangkan.

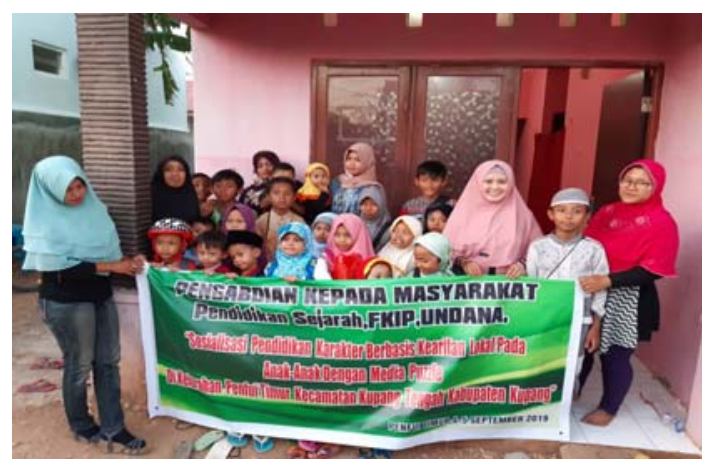

Gambar 4. Peserta, fasilitator dan orangtua

(Sumber: Dokumentasi Pribadi, 2019)

\section{SIMPULAN DAN SARAN}

Berdasarkan hasil di atas dapat disimpulkan bahwa puzzle berbasis kearifan lokal memuat nilai-nilai karakter sebagai salah satu sarana dalam mengembangkan karakter pada anak-anak. Dengan pertimbangan bahwa anakanak lebih menyukai permainan ini karena dianggap menarik dan tidak membosankan. Dengan media puzzle tersebut mereka dapat melihat gambar-gambar alat musik asli dari NTT, Tenun Ikat Asli NTT, Sasando dan berbagai kearifan lokal masyarakat NTT lainnya.. Sehingga ada sesuatu yang dapat diambil sebagai nilai karakternya. Selain itu kami selingi dengan beberapa permainan bukan pendidikan formal seperti yang didapat anak-anak di sekolah. Untuk itulah media puzzle dapat dijadikan alternative atau solusi dalam memberikan pendidikan karakter pada anak-anak. Kegiatan ini juga bisa dijadikan sosialisasi kebudayaan kepada anak-anak pendatang dari luar NTT sehingga mereka mengetahui dan belajar budaya NTT yang ternyata syarat akan pendidikan karakter.
Pendidikan karakter itu sangatlah penting dan perlu diberikan sejak dini agar mereka memiliki karakter yang baik dan kuat dalam menghadapi era global dan tidak tercabut dari akar budaya mereka. Anak-anak di kelurahan Penfui Timur diharapkan dapat mengaplikasikan semua pendidikan dan pesan moral yang telah diberikan agar mereka cerdas secara spiritual, akademik dan emosional. Dalam kehidupan sehari-haripun mereka dapat menentukan mana yang baik dan mana yang tidak baik. Dengan demikian diharapkan anak-anak menjadi generasi unggul berprestasi dan bermoral sesuai dengan harapan pemerintah.

\section{DAFTAR RUJUKAN}

Arief S. Sadiman, et al. (2009). Media Pendidikan: pengertian, pengembangan dan pemanfataannya. Jakarta: Rajawali Pers.

Azhar Arsyad. 2006. Media Pembelajaran, Jakarta: PT. Raja Grafindo.

Dooley, D., 1984, Social Research Method, Englewood Cliffs, N.J.: Prentice Hall, Inc.

Indriana, Dina. 2011. Ragam Alat Bantu Media Pengajaran. Yogyakarta: Diva Press.

Koesoema, Doni, A. 2010. Pendidikan Karakter Strategi Mendidik Anak di Zaman Global, Jakarta: Grasindo.

Lickona, Thomas. 1992. Educating For Character How Our School Can Teach Respect and Responsibility. New York: Bantam Books.

Pusat Pengembangan Kurikulum. 2011. Pedoman Pengembangan Pendidikan Budaya dan Karakter Bangsa bagi Sekolah. Jakarta: Kementerian Pendidikan Nasional

Miles, M.B., and Huberman, A.M. 1987. Qualitative Data Analysis: A Sourcebook of New Methods, Newbury Park: Sage Publication.

Moleong J. Lexy. 2000. Metode Penelitian Kualitatif. Bandung: PT Remaja Rosda Karya.

Shimahara, N., 1988, Anthroethnography: A Methodological Consideration. In R.R., Sherman and R.B. Webb, Qualitative Research in Education, Focus and Method, London: Falmer Press.

Spradly, J. 1997. James p. Spradley, Metode Etnografi. Penerbit: PT. Tiaara Wacana Yogya, 1997. 
Volume 3, Nomor 1, November 2019. p-ISSN : 2614-5251 e-ISSN : 2614-526X

Sutopo, H. B. 2006. Metode Penelitian kualitatif. Universitas Sebelas Maret Press, Surakarta.

Vredenbregt J.1980. Metode dan Teknik Penelitian Masyarakat. Jakarta: PT Gramedia. 